\title{
Outcome of Immediate Interventions in Acute Dysfunctional Hemodialysis Fistulas
}

\author{
Evaluation sofortiger Interventionen in akut dysfunktionellen \\ Hämodialyseshunts
}

Authors

Affiliations
P. J. Schaefer ${ }^{1}$, T. Jahnke ${ }^{2}$, S. Müller-Hülsbeck ${ }^{3}$, A. M. Wulff ${ }^{1}$, B. Sattler ${ }^{1}$, M. Schmidt ${ }^{1}$, M. Siggelkow ${ }^{4}$, F. K. W. Schaefer ${ }^{1}$

Diagnostic Radiology, University Hospital Schleswig-Holstein Campus Kiel, Kiel

Diagnostic and Interventional Radiology, Friedrich-Ebert-Hospital, Neumuenster

Diagnostic and Interventional Radiology, DIAKO Hospital, Flensburg

${ }^{4}$ Heart and Vascular Surgery, University Hospital Schleswig-Holstein Campus Kiel, Kiel

\author{
Key words \\ - vascular \\ - interventional procedures \\ - efficacy studies \\ - hemodialysis fistula
}

eingereicht 20.3.2012

akzeptiert $\quad 12.10 .2012$

\section{Bibliography}

Dol http://dx.doi.org/

10.1055/s-0032-1330274

Published online: 10.12.2012

Fortschr Röntgenstr 2013; 185:

228-234 ๑ Georg Thieme

Verlag KG Stuttgart · New York . ISSN 1438-9029

\section{Correspondence \\ Dr. Philipp Jost Schaefer}

Diagnostic Radiology, University

Hospital Schleswig-Holstein

Campus Kiel

Arnold-Heller-Straße 3 (Haus 23)

24105 Kiel

Germany

Tel.: ++ 49/431/5974432

Fax: ++49/431/5973790

jostphilipp@web.de

\section{Zusammenfassung}

$\nabla$

Ziel: Evaluation der interventionellen Revision akut dysfunktioneller Dialyseshunts bei sofortiger Intervention wie von European Best Practice Guidelines for Hemodialysis empfohlen.

Material und Methoden: Über 3 Jahre wurden alle $(\mathrm{n}=280)$ Patienten mit akut dysfunktionellem Dialyseshunt unabhängig von der Tageszeit zur Angiografie vorgestellt. Eine Angiografie und, falls möglich, interventionelle Revision wurden bei $n=241$ Fällen durchgeführt. Es wurden 3 Beobachtungsgruppen gebildet: Erfahrungsgrad des Interventionalisten (hoch/niedrig), Tageszeit (Routinearbeitszeit, 7-16h; Notdienstzeit, 16-7h), Läsionsart (Stenose/fibrosklerotischer Verschluss/thrombotischer Verschluss/kombiniert Stenose+Thrombose). Für die statistische Analyse wurden die korrespondierenden Erfolgsraten, Chi-Quadrat-Tests $(p<0,025)$ und eine logistische Regressionsanalyse $(p<0,05)$ berechnet.

Ergebnisse: Die Gesamterfolgsrate betrug 62\% (149/241). Die Erfolgsraten waren nach Interventionalist für hohen/niedrigen Erfahrungsgrad 71\% (79/111)/54\% (70/130), $\mathrm{p}=0,022$; nach Tageszeit für Routinearbeitszeit/Notdienstzeit $68 \%$ (93/ 136)/53\% (56/105), p =0,017; nach Läsionsart für Stenose/fibrosklerotischen Verschluss/thrombotischen Verschluss/kombiniert Stenose+Thrombose $82 \%(94 / 104) / 39 \%(13 / 33) / 18 \%$ (6/33)/59\% (36/ $61), p<0,001$. In der logistischen Regressionsanalyse waren relevante Variablen hoher Erfahrungsgrad und die Läsionsarten Stenose und kombiniert Stenose+Thrombose mit einer Odds Ratio von 2,300 $(p=0,012), 12,053(p<0,001), 3,189(p=0,003)$.

Schlussfolgerung: Eine uneingeschränkte Umsetzung sofortiger Interventionen bei akut dysfunktionellen Dialyseshunts erfordert die permanente Bereitschaft eines Interventionalisten mit hohem Erfahrungsgrad. Die Läsionsarten fibrosklerotischer und thrombotischer Verschluss bieten nur geringe Erfolgsraten bei interventioneller Revision.

\section{Abstract \\ V}

Purpose: To analyze the efficacy of interventions in acute dysfunctional hemodialysis fistulas, if intervention is performed immediately as recommended by European Best Practice Guidelines for Hemodialysis.

Materials and Methods: Over 3 years, all $(n=280)$ patients with an acute dysfunctional hemodialysis fistula were immediately referred to angiography, irrespective of the time of day. Angiography and, if possible, interventional revision $(n=241)$ were performed. Three groups of interest were established: interventionalist's experience (high/low), time of day (routine hours: $7 \mathrm{am}-4 \mathrm{pm} /$ emergency hours: $4 \mathrm{pm}-7 \mathrm{am}$ ), lesion type (stenosis/fibrosclerotic occlusion/thrombotic occlusion/combined stenosis+thrombotic occlusion). For statistical analysis corresponding success rates, chisquare tests $(\mathrm{p}<0.025)$ and logistic regression analysis $(p<0.05)$ were calculated.

Results: The total success rate was $62 \%(149 / 241)$. The success rates were: interventionalist experience high/low $71 \%(79 / 111) / 54 \%(70 / 130), \quad p=0.022$; time of day routine/emergency hours $68 \%$ (93/ 136)/53\% (56/105), $p=0.017$; lesion type stenosis/ fibrosclerotic occlusion/thrombotic occlusion/combined stenosis+occlusion $82 \%(94 / 104) / 39 \%(13 /$ 33)/18\% (6/33)/59\% (36/61), p<0.001. Relevant variables due to logistic regression analysis were high experience and the lesion types stenosis and combined stenosis+occlusion with odds ratios $2.300(p=0.012), 12.053(p<0.001), 3.189$ $(\mathrm{p}=0.003)$.

Conclusion: Unrestricted implementation of immediate interventions in acute dysfunctional hemodialysis fistulas requires permanent availability of experienced interventionalists. The lesion types fibrosclerotic occlusion and thrombotic occlusion offer poor success rates for interventional revision. 


\section{Introduction}

\section{$\nabla$}

Although renal transplantation is considered the therapy of choice for patients with end-stage renal disease (ESRD), ESRD patients are often put on long-term hemodialysis [1, 2]. For permanent hemodialysis access surgically created native arteriovenous (AV) fistulas are commonly used [3 - 5]. Adequate care of an ESRD hemodialysis patient includes constant attention to the need to maintain vascular access patency. Hemodialysis access failure is a major cause of morbidity for ESRD patients on hemodialysis, resulting in an increased number of patient hospitalizations, prolonged hospitalizations and thus increasing costs [6]. Dysfunctional AV fistulas often result in thrombosis of the vascular access as the final complication. As recommended by the Kidney Disease Outcomes Quality Initiative (KDOQI) guidelines of the American National Kidney Foundation, treatment of thrombosis should start as early as possible to maintain long-term patency of the vascular access [6]. The optimal timing of the treatment of the underlying causes for dysfunction, such as arterial, anastomotic and venous stenosis or fibrosclerotic occlusion of the vein, is not specified by the KDOQI guidelines and remains to be determined [7]. Due to the European Best Practice Guidelines (EBPG) for Hemodialysis of Nephrology Dialysis Transplantation Education, pre-emptive intervention should be performed immediately in the case of dysfunction [8]. Thus, there is a certain discrepancy among the available major guidelines, and, in our opinion, immediate interventional revision would be influenced by a setting on an emergency basis.

For a period of three years, we followed the EBPG: All ESRD hemodialysis patients with acute dysfunctional AV fistulas were immediately referred to the radiological intervention center, irrespective of the time of day, the available interventionalist and the lesion type. We analyzed our data to prove the efficacy of radiological interventions in this "emergency setting".

\section{Materials and Methods}

$\nabla$

\section{Study Design and Patient Population}

Following the EBPG for a period of three years, all $(n=280)$ patients who presented in the local university hospital with an acute dysfunctional hemodialysis fistula were immediately referred to the radiological intervention center. Written informed consent was obtained from each patient. The patients were consecutively enrolled. The patients could reject the intervention at any time of the procedure. As soon as possible, angiography and, if deemed feasible, interventional treatment were performed, irrespective of the time of day, the interventionalist available, and the specific lesion type. In $n=241$ cases, an intervention was performed. Of the 280 patients, there were 141 men and 139 women. The mean age was 64 years (range: 26 - 91 years). Institutional Review Board approval was present for the data analysis.

\section{Angiography and Interventional Techniques}

All procedures were performed under local anesthesia. It was attempted to puncture the failing hemodialysis fistula initially with retrograde/ antegrade placement of an $18-\mathrm{G}$ catheter. If necessary for sufficient angiography, the brachial artery was punctured or catheterized via groin access in selected cases. Successive angiographies were conducted to obtain diagnostic image data covering the afferent arterial inflow, the perfusion of the hemo- dialysis fistula, and the efferent venous outflow up to the right heart ventricle. All patients were given an antithrombosis regimen with preinterventional injection of a 5000-IU intravenous heparin bolus.

Depending on the profile of the utilized interventional equipment, the sizes of the inserted sheaths ranged from 4-F to 8-F. Considering the location of the target lesion, an antegrade/retrograde approach via the hemodialysis fistula, an antegrade approach via the brachial artery or a transinguinal venous approach in selected cases of occlusion was chosen. Stenoses and occlusions were crossed with a hydrophilic 0.035 -inch or 0.018 -inch guide wire. Stenoses and fibrosclerotic occlusions were primarily dilated by plain balloon angioplasty. If that was insufficient with a residual stenosis of $30 \%$ or greater, cutting balloons were used. Thrombotic occlusions were aspirated manually, and aspiration was performed using 7-F and 8-F aspiration catheters and a 60$\mathrm{mL}$ syringe. If necessary in long thrombotic occlusions, two sheaths were placed in "criss-cross" technique. No stents were deployed in the AV fistulas, and no thrombolytic agents were administered. The fistula puncture sites were sealed using a double U-shaped suture with interposition of a tapered plastic introducer [9], and the arterial puncture sites were manually compressed until complete hemostasis. Futile interventional revisions of dysfunctional hemodialysis fistulas were immediately referred to surgical revision.

\section{Study Objectives}

Three groups of interest were set as the primary objectives for statistical analysis:

a) Time of day when the intervention was performed with the subgroups: routine working hours from 07:00 a.m. to 04:00 p. m. Monday through Friday and emergency working hours from 04:00 p.m. to 07:00a.m. including the entire weekend ( $\bullet$ Table 1 ).

b) Interventionalist's level of experience with the subgroups: low level and high level. The level definitions were based on the number of interventions in dysfunctional hemodialysis fistulas per interventionalist during a two-year period before study onset ( $\bullet$ Table 1 ).

c) Specific lesion type with the subgroups: stenosis, fibrosclerotic occlusion, thrombotic occlusion, and combination of stenosis and additional thrombotic occlusion ( $\bullet$ Table 1 ).

\section{Statistical Analysis}

Success was defined as a combination of initial technical success by angiographic evidence of a patent hemodialysis fistula and clinical success by at least one sufficient hemodialysis following intervention. For stenosis and fibrosclerotic occlusion, technical success was defined as residual stenosis of less than $30 \%$. For each subgroup of the three groups of interest, the corresponding success rates were calculated. Cross tables were established for each group of interest, and Pearson's chi-square tests were calculated to search for significant differences among the subgroups (two-sided asymptotic significance with $\mathrm{p}<0.05$ ). A logistic regression analysis was performed to detect the variables with considerable impact on the success rate, providing the corresponding odds ratios of the relevant subgroups. As the statistical software, SPSS (Version January 2010; Chicago, IL, USA) was used. 
Table 1 Definition of the three groups of interest with the specific subgroups. ${ }^{1}$

Tab. 1 Definition der 3 Beobachtungsgruppen mit den spezifischen Untergruppen. ${ }^{2}$

\begin{tabular}{|c|c|c|}
\hline group of Interest & subgroup & definition \\
\hline \multirow[t]{2}{*}{ time of day } & routine working hours & 07:00a. m. to 04:00 p. m. Monday through Friday \\
\hline & emergency working hours & $\begin{array}{l}\text { 04:00 p. m. to 07:00a. m. Monday through Friday and entire } \\
\text { weekend }\end{array}$ \\
\hline \multirow{2}{*}{ interventionalist's level of experience } & low & $\leq 30$ interventions \\
\hline & high & $>30$ interventions \\
\hline \multirow[t]{4}{*}{ lesion type } & stenosis & $\begin{array}{l}\text { stenosis } \geq 50 \% \text { at arteriovenous anastomosis, fistula or central } \\
\text { venous outflow }\end{array}$ \\
\hline & fibrosclerotic occlusion & occlusion by fibrosclerosis in fistula or central venous outflow \\
\hline & thrombotic occlusion & occlusion by thrombosis in fistula \\
\hline & combined stenosis/thrombotic occlusion & $\begin{array}{l}\text { combination of any stenosis and additional thrombotic } \\
\text { occlusion of fistula }\end{array}$ \\
\hline
\end{tabular}

${ }^{1}$ Note: The ranges for the level of experience represent the number of interventions in acute dysfunctional hemodialysis fistulas performed during a two-year period before study onset.

${ }^{2}$ Anmerkung: Zur Festlegung des Erfahrungsgrads wurde die Anzahl an Interventionen in akut dysfunktionellen Hämodialyseshunts in den 2 Jahren vor Studienbeginn herangezogen.

Table 2 Distribution of interventions for each subgroup in the three groups of interest.

Tab. 2 Verteilung der Interventionen je Untergruppe in den 3 Beobachtungsgruppen.

\begin{tabular}{|lll|}
\hline $\begin{array}{l}\text { group of } \\
\text { interest }\end{array}$ & subgroup & intervention rate \\
\hline time of day & routine working hours & $56 \%(136 / 241)$ \\
\hline & emergency working hours & $44 \%(105 / 241)$ \\
\hline $\begin{array}{l}\text { interventional- } \\
\text { ist's level of } \\
\text { experience }\end{array}$ & low & $54 \%(130 / 241)$ \\
\hline lesion type & high & $46 \%(111 / 241)$ \\
\hline & $\begin{array}{l}\text { stenosis } \\
\text { fibrosclerotic occlusion }\end{array}$ & $47 \%(114 / 241)$ \\
\hline & $\begin{array}{l}\text { thrombotic occlusion } \\
\text { combined stenosis/throm- } \\
\text { botic occlusion }\end{array}$ & $14 \%(33 / 241)$ \\
\hline & $25 \%(61 / 241)$ \\
\hline
\end{tabular}

\section{Results}

$\nabla$

\section{Intervention and Success Rates}

The distribution of the total $n=241$ interventions by the time of day group was 56\% (136/241) for routine working hours versus $44 \%$ (105/241) for emergency working hours ( $\bullet$ Table 2 ). For the level of experience group, 46\% (111/241) of the interventions were performed by interventionalists with a high level of experience and $54 \%$ (130/241) by ones with less experience ( Table 2 ). Concerning lesion type, most of the lesions treated were stenoses with $47 \%(114 / 241)$ of the cases, followed by the combination of stenosis and additional thrombotic occlusion ( Fig. 1) with $25 \%$ (61/241) of the cases ( 0 Table 2 ).

The success rate for interventions conducted during routine working hours was $68 \%(93 / 136)$ versus $53 \%(56 / 105)$ for those conducted during emergency working hours, with $p=0.017$ ( Table 3). Depending on the level of the interventionalist's experience, the highest success rate was found for a high level of experience with $71 \%(79 / 111)$ versus $54 \%$ (70/130) for a low level of experience, with $\mathrm{p}=0.022$ ( $\bullet$ Table 3 ). In the lesion type group, stenoses were very likely to be treated successfully with $82 \%$ (94) 114 ) of the cases. The combination of stenosis and additional thrombotic occlusion had a success rate of $59 \%(36 / 61)$, while
Table 3 Success rates for each subgroup in the three groups of interest.

Tab. 3 Erfolgsrate je Untergruppe in den 3 Beobachtungsgruppen.

\begin{tabular}{|c|c|c|c|}
\hline $\begin{array}{l}\text { group of inter- } \\
\text { est }\end{array}$ & subgroup & success rate & $\begin{array}{l}\text { Pearson's } \\
\text { Chi-square }\end{array}$ \\
\hline \multirow{3}{*}{$\begin{array}{l}\text { time of day } \\
\text { interventional- } \\
\text { ist's level of ex- } \\
\text { perience }\end{array}$} & routine working hours & $68 \%(93 / 136)$ & \\
\hline & $\begin{array}{l}\text { emergency working } \\
\text { hours }\end{array}$ & $53 \%(56 / 105)$ & \\
\hline & & & $p=0.017$ \\
\hline \multirow[t]{8}{*}{ time of day } & low & $54 \%(70 / 130)$ & \\
\hline & high & $71 \%(79 / 111)$ & \\
\hline & & & $p=0.022$ \\
\hline & stenosis & $82 \%(94 / 114)$ & \\
\hline & $\begin{array}{l}\text { fibrosclerotic } \\
\text { occlusion }\end{array}$ & $39 \%(13 / 33)$ & \\
\hline & thrombotic occlusion & $18 \%(6 / 33)$ & \\
\hline & $\begin{array}{l}\text { combined stenosis/ } \\
\text { thrombotic occlusion }\end{array}$ & $59 \%(36 / 61)$ & \\
\hline & & & $p<0.001$ \\
\hline
\end{tabular}

fibrosclerotic occlusions and especially thrombotic occlusions had low success rates of $39 \%$ (13/33) and $18 \%$ (6/33), respectively. The differences reached level of significance with $\mathrm{p}<0.001$ ( Table 3).

The specific success rates were significantly better for stenoses treated during routine working hours by experienced interventionalists with $94 \%$ (34/36) versus $74 \%$ (31/42) ( $\bullet$ Table 4$)$, with $\mathrm{p}<.001$. During emergency working hours, the success rates for stenoses were similar with $80 \%$ versus $81 \%$. The specific success rates were also significantly better for the combination of stenosis and additional thrombotic occlusion treated during routine working hours by experienced interventionalists with $84 \%$ (16/ 19) versus $60 \%$ (3/5) ( $\bullet$ Table 4$)$, with $p<0.001$. The corresponding success rates during emergency working hours were similar with $44 \%$ versus $48 \%$. However, the success rate decreased significantly for that lesion type from $84 \%$ during routine working hours to $44 \%$ during emergency working hours, if treated by experienced interventionalists ( Table 4 ). The majority of $5 / 6$ successfully treated thrombotic occlusions were treated by experienced interventionalists, independent of the time of day (॰ Table 4). 

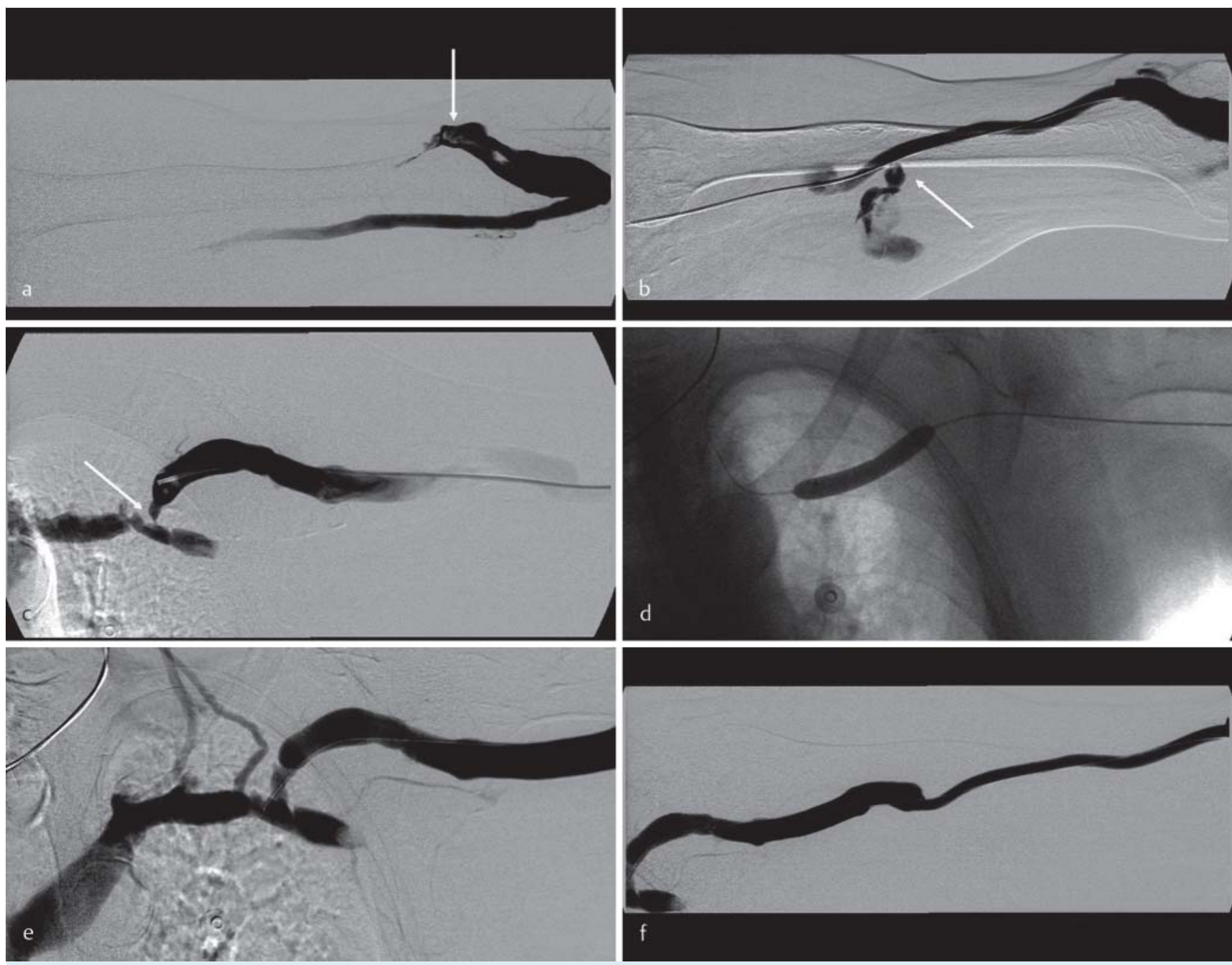

Fig. 1 64-year-old male ESRD patient with an interposed PTFE segment in a dysfunctional cephalic arteriovenous fistula on the left upper arm and a moderate hematoma after futile puncture for hemodialysis. Time of day, emergency working hours; interventionalist's level of experience, high; lesion type, combined stenosis and thrombotic occlusion. a The first angiogram confirms occlusion by thrombosis (white arrow), with the segment distal to the arteriovenous anastomosis patent. $\mathbf{b}$ After manual aspiration of thrombus, the control angiogram reveals active bleeding (white arrow) due to the futile puncture for hemodialysis. $\mathrm{c}$ Further manual aspiration reopens the fistula, and a severe stenosis at the conjunction of the cephalic into the subclavian vein (white arrow) can be detected as the underlying cause. d Dilation of the stenosis using an 8-mm balloon at an inflation pressure of $8 \mathrm{~atm}$. e, $\mathbf{f}$ After gentle compression of the bleeding site, the final angiograms demonstrate restored patency of the fistula.

Abb. 1 64-jähriger dialysepflichtiger Mann mit interponiertem PTFE-Graft in einem dysfunktionellen Cephalicashunt am linken Oberarm und einem mäßigen Hämatom nach frustraner Punktion zur Hämodialyse. Tageszeit: Notdienstzeit; Erfahrungsgrad Interventionalist: hoch; Läsionsart: kombiniert Stenose und thrombotischer Verschluss. a Die erste Angiografie zeigt einen thrombotischen Verschluss (weißer Pfeil) mit distal der arteriovenösen Anastomose offenem Segment. b Nach manueller Thrombusaspiration offenbart die Kontrollangiographie eine aktive Blutung (weißer Pfeil), entstanden nach frustraner Punktion zur Hämodialyse. c Weitere manuelle Aspiration eröffnet den Shunt wieder, und eine hochgradige Stenose am Eintritt der V. cephalica in die V. subclavia (weißer Pfeil) stellt sich als zugrunde liegende Ursache heraus. $\mathbf{d}$ Dilatation der Stenose mit einem $8 \mathrm{~mm}$-Ballon bei $8 \mathrm{~atm}$ Inflationsdruck. e, $\mathbf{f}$ Nach sorgfältiger Kompression der Blutungsquelle zeigt die Abschlussangiografie einen wiedereröffneten Shunt.

\begin{tabular}{|l|llll|}
\hline \multicolumn{2}{|l|}{ routine working hours } & \multicolumn{2}{l|}{ emergency working hours } \\
\hline & $\begin{array}{l}\text { high level of } \\
\text { experience }\end{array}$ & $\begin{array}{l}\text { low level of } \\
\text { experience }\end{array}$ & $\begin{array}{l}\text { high level of } \\
\text { experience }\end{array}$ & $\begin{array}{c}\text { low level of } \\
\text { experience }\end{array}$ \\
\hline stenosis & $94 \%(34 / 36)$ & $74 \%(31 / 42)$ & $80 \%(12 / 15)$ & $81 \%(17 / 21)$ \\
\hline fibrosclerotic occlusion & $38 \%(3 / 8)$ & $36 \%(4 / 11)$ & $57 \%(4 / 7)$ & $29 \%(2 / 7)$ \\
\hline thrombotic occlusion & $50 \%(2 / 4)$ & $0 \%(0 / 11)$ & $50 \%(3 / 6)$ & $8 \%(1 / 12)$ \\
\hline stenosis + thrombotic occlusion & $84 \%(16 / 19)$ & $60 \%(3 / 5)$ & $44 \%(7 / 16)$ & $48 \%(10 / 21)$ \\
\hline
\end{tabular}

Table 4 Cross table providing the distribution of the specific success rates for each subgroup.

Tab. 4 Kreuztabelle mit Verteilung der einzelnen Erfolgsraten der jeweiligen Untergruppen. 
Table 5 Logistic regression analysis providing the subgroups with relevant impact on the success rate.

Tab. 5 Darstellung der Untergruppen mit relevantem Einfluss auf die Erfolgsrate gemäß logistischer Regressionsanalyse.

\begin{tabular}{|llllrrr|}
\hline subgroup & $\begin{array}{l}\text { regression } \\
\text { coefficient }\end{array}$ & $\begin{array}{l}\text { standard } \\
\text { deviation }\end{array}$ & p-value & odds ratio & \multicolumn{1}{l|}{$\begin{array}{l}\text { lower bound } \\
\mathbf{9 5 \%} \mathrm{Cl}\end{array}$} & $\begin{array}{l}\text { upper bound } \\
\mathbf{9 5 \%} \mathrm{Cl}\end{array}$ \\
\hline high level of experience & 0.833 & 0.332 & 0.012 & 2.300 & 1.199 & 4.410 \\
\hline stenosis & 2.489 & 0.375 & $<0.001$ & 12.053 & 5.774 & 25.158 \\
\hline $\begin{array}{l}\text { combined stenosis/thrombotic } \\
\text { occlusion }\end{array}$ & 1.160 & 0.386 & 0.003 & 3.189 & 1.495 & 6.802 \\
\hline
\end{tabular}

\section{Specific Findings for Lesion Types} Fibrosclerotic occlusion

20/33 lesions were located on the upper arm and 13/33 lesions on the forearm, with success rates of $45 \%(9 / 20)$ and $31 \%(4 / 13)$, respectively. Among the 20 failed interventions, 3 cases were discontinued due to periinterventional perforation, strong pain, and wound healing deficit along the target lesion, respectively. 7/20 cases were occlusions of $10 \mathrm{~cm}$ or longer with additional extensive collaterals, 4/20 extending to the central venous outflow, 3/ 20 hemodialysis fistulas having not matured, and 2/20 sustained recoiling even not responding to cutting balloons. One case failed due to an additional occlusion of the brachial artery, which could not be crossed.

\section{Thrombotic occlusion}

$17 / 33$ lesions were located on the upper arm with $3 / 17$ successful interventions, and 16/33 lesions were located on the forearm with $3 / 16$ successful interventions. Three interventions were discontinued and referred to surgical revision due to periinterventional complications, with two cases of embolism of thrombotic material in the arterial vasculature and with one case of persistent bleeding at a puncture site. In 24 cases, the dysfunction was rated as early failure with occurrence of thrombosis within 60 days of creation, and the corresponding success rate was $17 \%$ (4/ 24). Of these 24 cases, 10 cases had a thrombosis age of one week or older and failed, 8 cases had an unclear thrombosis age and failed, and 6 cases had a thrombosis age of up to one week with four successful interventions. Six cases of thrombotic occlusion were mature hemodialysis fistulas, with a success rate of $33 \%$ (2/6). Of these six cases, three cases had a thrombus age of one week or older and failed, two cases had an unclear thrombus age with one successful intervention, and one case had a thrombus age of less than one week with successful intervention.

\section{Combination of stenosis and additional thrombotic occlusion}

$36 / 61$ lesions were located on the upper arm and 25/61 lesions on the forearm, with success rates of $64 \%(23 / 36)$ and $52 \%(13 /$ 25 ), respectively. Among the 25 failed interventions 4 cases were discontinued due to periinterventional perforation, embolism of thrombotic material in the arterial vasculature, arterial vasospasm of the afferent radial artery, and strong pain, respectively. 10/25 cases had a thrombus age of one week or older, and $2 / 25$ an unclear thrombus age. 4/25 cases had additional fibrosclerotic occlusions extending to the central venous outflow. $3 /$ 25 cases were rated as early failure with occurrence of the lesions within 60 days of creation. One case failed due to sustained recoiling, even not responding to cutting balloons, and one case due to additional occlusion of the radial artery, which could not be crossed. Among the 36 successful interventions, 26/36 cases had a thrombus age of less than one week, 4/36 a thrombus age of one week or older, and 6/36 an unclear thrombus age.

\section{Logistic Regression Analysis}

The predictability, which means to predict the outcome of the intervention under the influence of the abovementioned variables of the three groups of interest, was $73 \%$ (177/241) for the total of $\mathrm{n}=241$ cases, $79 \%(117 / 149)$ to achieve success during the intervention, and $65 \%(60 / 92)$ for no success. In the logistic regression analysis, the variable high level of experience proved to be relevant with an odds ratio of 2.300 , the lower bound of the $95 \%$ confidence interval $(\mathrm{CI})$ at 1.199 and the upper bound of the $95 \% \mathrm{CI}$ at 4.410 ( $\bullet$ Table 5). There were two variables among the four subgroups of lesion types that had a relevant impact on the success rate. The calculated odds ratio for the variable combination of stenosis and additional thrombotic occlusion was 3.189 with the lower bound of the $95 \% \mathrm{CI}$ at 1.495 and the upper bound of the $95 \% \mathrm{Cl}$ at 6.802 , while the odds ratio for the variable stenosis reached the highest level of 12.053 with the lower bound of the $95 \% \mathrm{CI}$ at 5.774 and the upper bound of the $95 \% \mathrm{CI}$ at 25.158 (๑ Table 5).

\section{Discussion}

$\nabla$

Patent vascular access is the basic prerequisite for adequate hemodialysis in patients with ESRD for sustaining quality of life and long-term survival [10]. As the anatomical locations for creating hemodialysis fistulas are limited, both the maintenance and the salvage of dysfunctional AV fistulas are key issues in the long-term care of ESRD patients. In the last two decades, there has been a gradual shift in the management of dysfunctional hemodialysis fistulas, with interventional radiology today playing the leading role in first-line treatment [7, 10-13]. Interventional revision of dysfunctional hemodialysis fistulas ( $\bullet$ Fig. $\mathbf{1}$ ) represents the least invasive procedure to re-establish sufficient blood flow, as compared to the alternative of surgical revision [7]. Numerous prospective and retrospective studies have demonstrated the value of an endovascular approach in salvaging hemodialysis fistulas with technical success rates of more than $90 \%$ for dilation of stenoses $[7,10,12-17]$ and of up to $90 \%$ for declotting of thrombosed hemodialysis fistulas [7, 10, 18-25].

When reviewing the major guidelines for hemodialysis access, the EBPG and the KDOQI, we see a controversy that needs to be resolved. While it is stated in the EBPG that dysfunctional hemodialysis fistulas, without any further specification in terms of the lesion type, should be treated immediately [8], the KDOQI guidelines only specify that the thrombosed fistula should be treated urgently, and do not address optimal timing for other lesion types [6]. Furthermore, immediate revision of dysfunctional he- 
modialysis fistulas would certainly be affected by an emergency setting, probably with a negative impact on the outcome. We designed our analysis to address this issue of the influence on the success rate when intervention is performed irrespective of the time of day, irrespective of the level of experience of the interventionalist available at that time, and irrespective of the specific lesion type.

For the group of interest "time of day", we found interventions being performed during routine working hours offer a significantly higher success rate than those during emergency working hours, with $\mathrm{p}=0.017$. However, a closer look at the results of the logistic regression analysis did not prove that the time of day has a considerable impact on the success rate in our setting. This indicates that the relatively better results during routine working hours cannot easily be explained by better staffed teams in the angiographic theater during regular working hours versus only minimally staffed teams during emergency working hours. We consider the below mentioned factor "level of experience" to create this bias towards better results during routine working hours. For the group of interest "level of experience", there were significant differences in the success rates between a low and high level of experience, with $p=0.022$, which, of course, could have been expected. In the logistic regression analysis, a high level of experience was one of the three factors with relevant impact on the outcome of interventions in dysfunctional hemodialysis fistulas, with an odds ratio of 2.300. This underlines the importance of an experienced interventionalist treating complex lesions in dysfunctional hemodialysis fistulas in ESRD patients as presented in 0 Fig. 1. It is obvious that the most experienced interventionalists would be available more often during routine working hours than during emergency working hours, thus explaining the different success rates with respect to the time of day. For the group of interest "lesion type", the success rates of the specific lesion types differed significantly, with $\mathrm{p}<0.001$. With an overall success rate of $82 \%$, the stenosis lesion type proved to have a high likelihood of being treated successfully. Our results indicate that if thrombotic events occur in addition to an underlying stenosis, the success rate decreases considerably down to a rate of $59 \%$ for the combination of stenosis and additional thrombotic occlusion.

Compared to data published in the literature with reported success rates of above $90 \%$ for stenosis treatment [7, 10, 12 - 17], the overall rate of $82 \%$ in our study remains somewhat lower, but the rate of $94 \%$ for stenoses treated during routine working hours by experienced interventionalists is equivalent to the literature. Our overall success rate of $59 \%$ for the treatment of stenosis and additional thrombosis, however, is considerably lower than the published results of up to $90 \%[7,10,19-21]$. Again, the rate of $84 \%$ for lesions treated during routine working hours by experienced interventionalists corresponds to the literature. We see the abovementioned emergency setting as the major reason for our overall lower results, as the only acceptable success rate of $84 \%$ across all variables for this subgroup is found for interventions performed during routine working hours by experienced interventionalists. Additionally, only manual aspiration maneuvers were performed in clotted hemodialysis fistulas. Maybe, the use of mechanical thrombectomy devices could have offered better results, as reported in the literature [19-21]. The thrombus age had a considerable influence on the outcome of the intervention, as there was a high proportion of $40 \%$ (10/25) of the cases with older thrombus among the failed interventions, and a high proportion of $72 \%(26 / 36)$ of the cases with fresh thrombus among the successful interventions. Nevertheless, the lesion type combination of stenosis and additional thrombosis with an odds ratio of 3.189 and the lesion type stenosis with the very high odds ratio of 12.053 had a relevant influence on the success in our analysis.

Fibrosclerotic occlusions, usually caused by repeated punctures [26] along the AV fistula for hemodialysis over a long period of time, showed a fairly low success rate of $39 \%$. The majority of $55 \%(11 / 20)$ of the failed interventions were long lesions with extensive collaterals or extending to the central venous outflow, indicating chronically progressive disease. Recently, Chen et al. reported a similarly low success rate of $46 \%$ in their study population for reopening occluded fibrosclerotic lesions [27]. If interventional recanalization of these occluded fibrosclerotic segments of AV fistulas fails via both antegrade and retrograde approach, surgical revision should be sought early to avoid the formation of extensive collateralization. There were three mentionable cases each of failed interventions in hemodialysis fistulas having not matured in the subgroups, fibrosclerotic occlusion and combination of stenosis and additional thrombotic occlusion. Sheer thrombotic occlusions were very unlikely to be treated successfully with a total success rate of only $18 \%$. The high proportion with 24 cases of early failure of hemodialysis fistulas among thrombotic occlusions may explain the discouraging success rate. The thrombus age also has to be considered as a relevant factor with the majority of cases with older thrombus among the failed interventions and with almost all successful interventions at fresh thrombus. Unfortunately, a sheer thrombotic occlusion may not be distinguished from the combination of stenosis and thrombotic occlusion as the thrombosis usually masks the underlying stenosis. Thus, it is not possible to state that sheer thrombosis should immediately be referred to surgical revision. In a recent study by Yurkovic et al., similarly low success rates of only up to $17 \%$ are reported for declotting hemodialysis grafts [18]. Mudunuri et al. found similarly poor primary and cumulative patency for thrombectomy of early graft failure, stating it may not be worthwhile [28]. However, they focused on early graft failure and investigated the outcomes of thrombectomy procedures, thus their results cannot easily be compared to ours. Additional investigations have to follow to understand the pathomechanism of thrombosis in hemodialysis fistulas, and more efficacious techniques have to be indentified for interventional revision of that lesion type [18].

There are several limitations in this study that should be addressed. First, it was not planned and conducted as a prospective, randomized trial, but only as an observational study with consecutive patient enrollment. Second, we did not check for the patency rates of the treated hemodialysis fistulas, which, however, was not mandatory to target the study's objective. Third, it remains unclear whether the results for declotting sheer thrombosis could have been better, if other declotting equipment and thrombolytic agents would have been utilized rather than just performing manual aspiration maneuvers.

Our study offers results for interventions in acute dysfunctional hemodialysis fistulas in a real life setting. We do not recommend unrestricted implementation of the EBPG in terms of immediate interventional revision, as our results suggest the availability of an experienced interventionalist, which has recently be highlighted by the Qualification Guideline of the DRG and DeGIR [29] and is more likely during routine working hours. Furthermore, the decrease in the success rates from stenosis to stenosis with additional thrombosis emphasizes the need to avoid any thrombotic 
event, since thrombosis may become impossible to resolve [11]. The success rates for fibrosclerotic and thrombotic occlusions remain unsatisfactory.

\section{References}

1 Kuhlemann J, Blondin D, Grotemeyer D et al. Gadofosveset-enhanced MR imaging for the preoperative evaluation of potential living kidney donors: correlation with intraoperative findings. Fortschr Röntgenstr 2010; 182: 1001 - 1009

2 Mathys C, Blondin D, Wittsack HJ et al. T2' imaging of native kidneys and renal allografts - a feasibility study. Fortschr Röntgenstr 2011; 183: $112-119$

3 Froger CL, Liem YS, Tielbeek AV et al. Stenosis detection with MR angiography and digital subtraction angiography in dysfunctional hemodialysis access fistulas and grafts. Radiology 2005; 234: 284-291

4 Wacker FK, Lipuma J, Blum A. Alternative Zugangswege für Hämodialysekatheter bei Patienten mit verschlossenen peripheren venösen $\mathrm{Zu}-$ gangswegen. Fortschr Röntgenstr 2005; 177: 1146-1150

5 Gibbens DT, Triolo J, Yu T et al. Contemporary treatment of thrombosed hemodialysis grafts. Tech Vasc Interv Radiol 2001; 4: $122-126$

6 National Kidney Foundation. Clinical practice guidelines for vascular access. Am J Kidney Dis 2006; 48: S176 -S247

7 Surlan $M$, Popovic $P$. The role of interventional radiology in management of patients with end-stage renal disease. Eur J Radiol 2003; 46: $96-114$

8 Nephrology Dialysis Transplantation Educational. European Best Practice Guidelines for Haemodialysis. Nephrol Dial Transplant 2007; 22: ii88-ii117

9 Turmel-Rodrigues LA. Declotting a thrombosed Brescia-Cimino fistula by manual catheter-directed aspiration of the thrombus. Cardiovasc Intervent Radiol 2005; 28: 10-16

10 Bent CL, Sahni VA, Matson MB. The radiological management of the thrombosed arteriovenous dialysis fistula. Clinical Radiology 2011; 66: $1-12$

11 Notario A, Turmel-Rodrigues L, Fodil-Cherif $M$ et al. Endovascular treatment of immature, dysfunctional and thrombosed forearm autogenous ulnar-basilic and radial-basilic fistulas for haemodialysis. Nephrol Dial Transplant 2010; 25: 532-538

12 Tapping CR, Mallinson PI, Scott PM et al. Clinical outcomes following endovascular treatment of the malfunctioning autologous dialysis fistula. J Med Imaging Radiat Oncol 2010; 54: 534-540

13 Schaefer PJ, Müller-Hülsbeck S, Schaefer FK et al. Verlängert die radiologisch-interventionelle Therapie die Shuntnutzungsdauer bei hämodialysepflichtigen Patienten? Fortschr Röntgenstr 2006; 178: 1121 1127

14 Manninen HI, Kaukanen ET, Ikaheimo R et al. Brachial arterial access: endovascular treatment of failing Brescia-Cimino hemodialysis fistulas - initial success and long-term results. Radiology 2001; 218: 711-718
15 Clark TW, Hirsch DA, Jindal KJ et al. Outcome and prognostic factors of restenosis after percutaneous treatment of native hemodialysis fistulas. J Vasc Interv Radiol 2002; 13: 51 -59

16 Rajan DK, Bunston S, Misra S et al. Dysfunctional autogenous hemodialysis fistulas: outcomes after angioplasty - are there clinical predictors of patency? Radiology 2004; 232: 508-515

17 Turmel-Rodrigues L, Boutin JM, Camiade C et al. Percutaneous dilation of the radial artery in nonmaturing autogenous radio-cephalic fistulas for hemodialysis. Nephrol Dial Transplant 2009; 24: 3782 - 3788

18 Yurkovic A, Cohen AD, Mantell MP et al. Outcomes of thrombectomy procedures performed in hemodialysis grafts with early failure. J Vasc Interv Radiol 2011; 22: 317-324

19 Trerotola SO, Vesely TM, Lund GB et al. Treatment of thrombosed hemodialysis access grafts: Arrow-Trerotola percutaneous thrombolytic device versus pulse-spray thrombolysis. Arrow-Trerotola Percutaneous Thrombolytic Device Clinical Trial. Radiology 1998; 206: 403-414

20 Trerotola SO, Ponce P, Stavropoulos SW et al. Physical examination versus normalized pressure ratio for predicting outcomes of hemodialysis access interventions. J Vasc Interv Radiol 2003; 14: 1387-1394

21 Lazzaro CR, Trerotola SO, Shah $\mathrm{H}$ et al. Modified use of the arrow-trerotola percutaneous thrombolytic device for the treatment of thrombosed hemodialysis access grafts. J Vasc Interv Radiol 1999; 10: $1025-1031$

22 Windus DW. Permanent vascular access: a nephrologist's view. Am J Kidney Dis 1993; 21: 457-471

23 Turmel-Rodrigues L, Raynaud A, Louail B et al. Manual catheter-directed aspiration and other thrombectomy techniques for declotting native fistulas for hemodialysis. J Vasc Interv Radiol 2001; 12: 1365-1371

24 Sahni V, Kaniyur S, Malhotra A et al. Mechanical thrombectomy of occluded hemodialysis native fistulas and grafts using a hydrodynamic thrombectomy catheter: preliminary experience. Cardiovasc Intervent Radiol 2005; 28: 714-721

25 Littler P, Cullen N, Gould D et al. Angiojet thrombectomy for occluded dialysis fistulae: outcome data. Cardiovasc Intervent Radiol 2009; 32: $265-270$

26 Lenhart M, Schätzler S, Manke C et al. Radiologische Implantation zentralvenöser Portsysteme am Unterarm. Implantationsergebnisse und Langzeit-Follow-up bei 391 Patienten. Fortschr Röntgenstr 2010; 182: $20-28$

27 Chen SM, Hang CL, Yip HK et al. Outcomes of interventions via a transradial approach for dysfunctional Brescia-Cimino fistulas. Cardiovasc Intervent Radiol 2009; 32: 952-959

28 Mudunuri V, O'Neal JC, Allon M. Thrombectomy of arteriovenous dialysis grafts with early failure: is it worthwile? Semin Dial 2010; 23: 634-637

29 Bücker A, Gross-Fengels W, Haage P et al. Qualifizierungsleitlinie der Deutschen Röntgengesellschaft (DRG) und der Deutschen Gesellschaft für Interventionelle Radiologie und minimalinvasive Therapie (DeGIR) zur Durchführung interventionell-radiologischer minimalinvasiver Verfahren an Arterien und Venen. Fortschr Röntgenstr 2012; 184: $565-569$

\section{Dedication}

Herrn Prof. Heller zur Emeritierung gewidmet. 